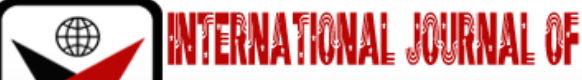 \\ בmRक
}

ISSN 2278-0211 (Online)

\section{Effect of IT Personnel Capability on Performance of Manufacturing Firms in Nairobi City County, Kenya}

\begin{tabular}{|c|}
\hline Lucy Gitau \\
Ph.D. Candidate, Department of Management Science, Kenyatta University, Kenya \\
Dr. David Nzuki \\
Lecturer, Department of Management Science, Kenyatta University, Kenya \\
Dr. Felix Musau \\
Professor, Department of Computing, Riara University, Kenya
\end{tabular}

\begin{abstract}
:
Manufacturing firms have reported dismal performance even after heavily investing in information technology (IT). Notably, this sector plays an important role in driving economic development by stimulating and sustaining high productive growth boosting employment opportunities for semi-skilled labour and building the country's' competitiveness. The manufacturing sector, respond to the surrounding conditions through deployment of appropriate strategic capabilities to overcome challenges, enhance their competitive position and sustain higher performance. Firms respond to the surrounding conditions by adjusting their purpose and shape through deployment of appropriate strategic capabilities to overcome the challenges enhance competitiveness and sustain superior performance. Several firms have made a huge investment in information technology (IT) to obtain economic value and to cope up with the ever-changing business environment. However, the economic value has not been attributed to IT personnel capability although IT personnel capability is one of the main drivers of sustainable firm performance. This paper applied cross sectional survey in collecting data from IT managers/ Chief Information Officers/ ICT directors drawn from manufacturing firms within Nairobi City County. The researcher used multistage sampling to identify regions where manufacturing firms are concentrated. A questionnaire was administered to 222 firms. A total of 140 valid responses were obtained.
\end{abstract}

Keywords: IT personnel capability, firm performance, manufacturing firms

\section{Introduction}

IT Personnel capability is the acquisition of technical skillset which includes professional skills and knowledge of technologies, technology management and business functions all of which enable them to undertake assigned roles effectively. The knowledge of technology is the understanding of an organization's IT resources namely networking, database management systems, programming languages and operating systems. Technology management refers to IT resource management which involves sensing, planning and redeployment of IT resources in response to changes in business environment. Knowledge of business functions is the deep understanding of the internal business processes and the business environment. IT personnel capabilities may also include acquisition of managerial skills and abilities to provide effective management of Information systems their synergy and collaboration with users. To grow such a knowledgeable workforce is a slow gradual process hence it's difficult for competitors to imitate over a short life span (Kim, 2010).

Bhatt \& Grover (2005) asserted that firms with strong IT personnel capabilities more effectively integrate IT and business planning process, conceive and develop reliable and cost-effective applications which then support business needs, better than their competitors. Further, Kim; Shin \& Kim (2011) were of the opinion that firms with competent IT staff have higher chances of meeting the demands of changing environments through the alignment of IT strategies with business strategies in order to develop reliable cost-effective systems. According to Makhloufi, Yaacob\&Yamin (2018) firms experience high business failure rate and low performance occasioned by incompetent IT personnel. According to Marinagi (2014) organizations, manufacturing firms included have been forced to align their IT resources to global completion, new technologies and customer demands. IT personnel capabilities provide unique expertise, competences and valuable business knowledge to support services.

\section{Literature Review}

Earlier research works argue that Resource-Based View (RBV) framework attempts to explain how organizations cope up with changing environment by processing resources which are of great value, inimitable, rare and nonsubstitutable. The fields of Management Science and Information Technology have criticized RBV due to its static nature. 
The framework of this paper is therefore supported by dynamic nature of Information Technology which will help explore the relationship between IT personnel capability and firm performance. According to Rojas (2017), dynamic capabilities timely support integration, reconfiguration and recombining of resources in order to adjust to environmental changes and demands.

\subsection{Firm Performance}

Firm Performance refers to the capacity to identify and implement the appropriate strategic objectives a firm is in pursuit of. According to Jacks (2011), IT capabilities help firms to gain competitive advantage over their competitors by increasing profits, reducing cost and recording high sale growth.Ferreira \&Otley (2009) posited that performance is determined by the strategies that improve firm's competitiveness, competitive advantage and creates superior performance. According to Teece\& Pisano (1997), firms integrate, reconfigure and rebuild strategies in order to create sustainable performance over competitors.

\subsection{IT Personnel Capability}

IT personnel capabilities comprise of professional skills, knowledge of technologies and technology management of IT staff which enable them to carry out assigned tasks effectively. Kim et. al. (2011) was of the opinion that the individual ability to contain knowledge about technical elements, IT resource management, business functions and ability to communicate and work with people would also be included. Bhatt \& Grover (2005) were of the opinion that firms with competent IT experts met competitive demands by aligning IT strategies with business strategies and developing cost effective systems that are reliable and aligned to IT needs for business services.

Bresnahan, Brynjolfsson\&Hitt (2002) observed that superior IT capability accompanies IT investment and skilled workforce leverage. The IT personnel in IT leader firms are more entrepreneurial and have better ideas for the innovative use of IT in business taking advantage of the IT assets. Chae, Koh\&Prybutok (2015) posited that the IT personnel can exploit the opportunities provided by new products or services. Mathias 2011; Nevo\& Wade (2010) were of the view that IT resources improve business performance if accompanied by other resources namely: effective organizational structure, productive culture and sufficient skills to leverage IT assets for business needs. Chaeet. al. (2015) recommended that these resources should be factored in future research to better understand the relationship between IT capability and firm performance. In addition, Muhanna\&Stoel (2010) observed that firms with stronger IT human capabilities such as technical and managerial IT skills are better able to make right decisions on IT spending, investment and development and are likely to turn such investments into value in terms of enhanced productivity and efficiency, improved marketing reflections, increased product differentiation and improved customer service.

Makhloufi, Yaacob\& Yasmin (2018) conducted a research on the effect of IT personnel capabilities on the sustainable competitive advantages within the furniture industry and in the context of developing economies. The rational of the study was to determine whether the technical skills and business knowledge influence firms to generate and sustain competitiveness. The study was anchored upon RBV while the informants were the IT managers. The study found out that IT personnel capabilities were the main drivers of sustainable competitiveness within the furniture firms. These authors asserted that firms experienced high business failure rate occasioned by incompetent IT personnel. The study findings concur with Ashrafi \& Mueller (2015) who posited that the technical skills and business knowledge considerably influence the functional and strategic levels of the firms.

Bett (2018) conducted a study to analyse the relationship between IS capabilities and firm performance in the telecommunication industry in Kenya. The study anchored and guided by resource-based theory and conceptual framework respectively, had firm performance as the dependent variable and IS capabilities as independent variable. The author used correlation and survey design. From a population of 408 staff comprising of executive and low-level operational managers, a sample of 202 staff was drawn through proportionate stratified random sampling method. The primary data was collected through a structured questionnaire and an interview schedule. The data was analysed using descriptive and inferential statistics. The findings showed a weak relationship between IS capabilities and firm performance. This study was anchored on RBV only a theory that focuses on the assets owned by a firm. However, little is said about how integration and reconfiguration of assets can contribute to firm performance in emerging markets an issue which the study strived to establish.

\section{Methodology}

The researcher used survey design to obtain data from IT managers/ Chief Information Officers/ ICT directors from manufacturing firms located in Nairobi City County so as to be able to explore the relationship between IT Personnel Capability and Firm performance. The data collection tool used in the study was a questionnaire administered to IT managers/ Chief Information Officers/ ICT directors in manufacturing firms that belong to either Building, Mining \& Construction, Chemicals \& Allied Sector, Energy, Electrical \& Electronics, Food \& Beverages, Leather \& Footwear, Metal \& Allied Sector, Motor Vehicle \& Accessories, Paper \& Board Sector, Pharmaceuticals \& Medical Equipment, Plastics \& Rubber, Fresh Produce, Textile \& Apparels and Timber, Wood \& Furniture Sector and located within the Nairobi City County.

The objective was to establish whether IT Personnel Capability has an influence on firm performance. Hypothesis $\mathrm{H}_{0}$ stated:

- $\mathrm{H}_{0}$ : There is no significant effect of IT Personnel Capability on performance of manufacturing firms in Nairobi City County. 


\section{Analysis and Findings}

\subsection{Respondents' Characteristics}

$66.4 \%$ were aged between 30- 49 years with $87.9 \%$ being males while the remaining $12.1 \%$ were females. Over $80 \%$ had a first degree or higher while majority (over $70 \%$ ) had a work experience of over 10 years.

\subsection{Hypothesis Test Results}

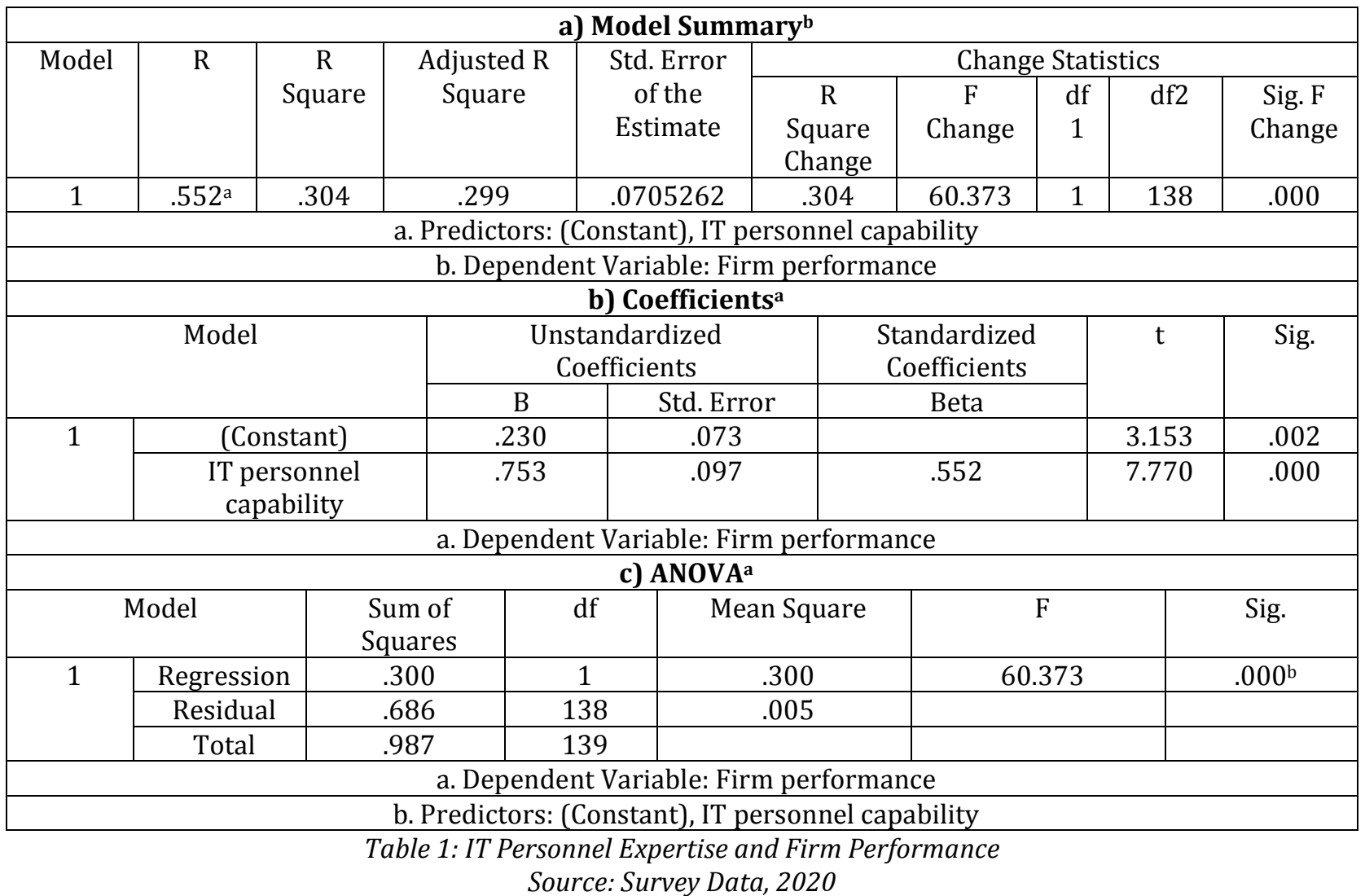

The regression model resulting from this test is:

Firm performance $=0.230+0.753$ IT personnel capability $+\epsilon$

The adjusted R squared shown in model (2) is 0.299, implying that IT personnel capability explains 29.9 per cent of the variation in firm performance. The $F$ statistic $F(1,138)=60.373, p=0.000$ is significant, suggesting that the model significantly explains the relationship between IT personnel capability and firm performance. The unstandardized beta coefficient for IT personnel capability is 0.753 while the constant has coefficient of 0.230 . This implies that a unit change in IT personnel capability changes the firm performance by a measure of 0.753 units while in a firm with low or no IT personnel capability, firm performance has a default value of 0.230 . The beta coefficient of IT personnel capability (0.753) is positively significant at $\mathrm{p}<0.05$ implying that there is a significant relationship between IT personnel capability and performance of manufacturing firms in Nairobi City County hence, the null hypothesis $\mathrm{H}_{2}$ is rejected.

The results are consistent with those of Deya, Oloko and Orwa (2015), Byrd (2004) who asserted that IT personnel should be knowledgeable about the key success factors in their institutions in order to cope with changing business demands. Further, Makhloufi and Al-Erjal (2014) asserted that IT personnel expertise is critical in utilizing IT resources which can lead to enhanced firm competencies, growth, survival and sustainable competitive advantage. Furthermore Makhloufi (2018) observed that IT personnel capability enable intangible IT resources (IT knowledge resources, IT relationship resources and IT governance) to support unique firm competencies which in turn lead to superior performance. IT personnel who possess sufficient and valuable IT knowledge in terms of technical, business and interpersonal skills are able to interpret customers' need and competitors' strategies better than their rivals. Gathungu and Mwangi (2012) asserted that IT personnel have the ability to identify and assess opportunities. Wang (2012) affirmed that IT personnel play an important role in the successful deployment of IT resources using their technical, business, and interpersonal skills. Moreover, firms which have strong IT human resources can develop reliable and cost-effective applications faster than their competitors.

\section{Conclusion}

The objective of this study was to establish the influence of IT personnel capability on firm performance in manufacturing firms in Kenya. Technology knowledge, technical management, business knowledge and relational knowledge were the indicators used in to investigate the relation between IT personnel capability and firm performance. 
The findings show that $29.9 \%$ of variation of firm performance is explained by IT personnel capability. Manufacturing firms strive to heavily invest in highly skilled personnel to enhance and sustain their performance.

\section{Implications for Practice}

The study findings are helpful to industrial players/owners in providing a better understanding of the role played by IT resources and capabilities in enhancing and sustaining superior performance. This knowledge can be used in policy formulation in manufacturing sector. Skilled IT personnel with business knowledge have the ability to sense and seize new business opportunities.

\section{References}

i. Bett, A. K., Obura, J. \&Oginda, M. (2018). Analysis of Information Systems Capabilities and Performance of firms in Telecommunications Industry, Kenya. International Journal of Scientific Research and Management. 6(4), 319327

ii. Bhatt, G. D., Grover, V. and Grover, V. (2005). Types of information technology capabilities and their role in competitive advantage: an empirical study. Journal of Management Information Systems, 22(2), 253-277.

iii. Chae H. C., Koh C. E., \&Prybutok V. R. (2014). Information technology capability and firm performance: contradictory findings and their possible causes. Mis Quarterly, 38(1), 305-326.

iv. Deya, J. Oloko, M. \&Orwa, G. (2015). The relationship between ICT capabilities and competitive advantage of Technical, Vocational and Entrepreneurship Training Institutions in Western Kenya Region. International journal of Academic Research $\quad$ in Business and Social Sciences. 5(8).2222-6990. Economic development in Africa report (2018)

v. Ferreira, A. \&Otley, D., 2009. The design and use of performance management systems: An extended framework for analysis. Management Accounting Research, 20(4),263-282.

vi. Gathungu, J., \&Mwangi, J.K. (2012). Dynamic Capabilities, Talent Development and Firm Performance.

vii. Kim, G., Shin, B., Kim, K. K., \& Lee, H. G. (2011). IT capabilities, process-oriented dynamic capabilities, and firm financial performance. Journal of the Association for Information Systems, 12(7), 487-517.

viii. Makhloufi, L., Yaacob N. A., \&Yamin, F. (2018). Effect of IT personnel expertise on the sustainable competitive advantages. Proceedings of the 2nd Conference on Technology \&Operations Management (2ndCTOM). Universiti Utara Malaysia.

ix. Marinagi Catherine (2014), 'The impact of information technology on the development of supply chain competitive advantage', Procedia-Social and Behavioral Sciences, Volume 147, August. $\quad$ 586-591.

x. Nevo, S., \& Wade, M. (2011). Firm-level benefits of IT-enabled resources: A conceptual extension and an empirical assessment. Journal of Strategic Information Systems, 20, 403-418. DOI: 10.1016/j.jsis.2011.08.001

xi. Teece, D. \& Pisano, G., 1997. The dynamic capabilities of firms: An introduction. Industrial and Corporate Change, 3(3), pp.537-556.

xii. Wang, N., Liang H., Zhong, Xue, W. \& Xiao, J. (2012) 'Resource structuring or capability building? An empirical study of the business value of information technology,' Journal of Management Information Systems, 29(1). 325-367, https://doi.org/10.2753/mis0742-1222290211. 